Asian J. Med. Biol. Res. 2021, 7 (1), 69-75; doi: 10.3329/ajmbr.v7i1.53311

\author{
Asian Journal of \\ Medical and Biological Research \\ ISSN 2411-4472 (Print) 2412-5571 (Online) \\ www.ebupress.com/journal/ajmbr
}

\title{
Article \\ The spleen of Sonali chicken: morphohistology and biometric analysis at post hatching ages
}

\author{
Ummay Ayman $^{1 *}$, Md. Rafiqul Alam² and Shonkor Kumar Das ${ }^{1}$ \\ ${ }^{1}$ Department of Anatomy and Histology, Faculty of Veterinary Science, Bangladesh Agricultural University, \\ Mymensingh, Bangladesh \\ ${ }^{2}$ Department of Surgery and Obstetrics, Faculty of Veterinary Science, Bangladesh Agricultural University, \\ Mymensingh, Bangladesh \\ *Corresponding author: Ummay Ayman, Assistant Professor, Department of Anatomy and Histology, Faculty \\ of Veterinary Science, Bangladesh Agricultural University, Mymensingh, Bangladesh. Phone: \\ +8801752635941; E-mail: ayman@bau.edu.bd
}

Received: 06 March 2021/Accepted: 28 March 2021/ Published: 31 March 2021

\begin{abstract}
Although Sonali chicken is introduced to the poultry industry of Bangladesh during 1999-2000 and after that playing a pivotal role in national economy, no literature is available regarding histomorphometry of spleen of Sonali chicken. As spleen is a key component of chicken's defense mechanism, the study was designed to investigate the age related development of spleen of Sonali chicken, i.e, morphohistology and biometry at several postnatal stages. The investigation was carried out on 25 healthy Sonali chickens representing different ages at after hacting days $1,14,28,42$, and $56(\mathrm{n}=5)$. After ethically sacrifice (cervical subluxation method), spleen was collected and subjected for both macro and microscopic examinations. Haematoxylin and Eosin stain was done for the later. Morphologically, spleen was found lying dorsally at the right side of the abdominal cavity. It was oval or rounded organ, reddish brown in color. The gross morphometric observations (average weight, organ index, length, width and thickness) found significantly increasing throughout the tenure $(\mathrm{p}<0.001)$. In microscopic study, no trabeculae and identifying marginal zone was recorded in the splenic parenchyma of Sonali chicken. And a component of white pulp (lymphatic nodules) appeared at day 14 onward. This study gives an insight about the age correlated development of spleen of Sonali chicken at different age intervals which advance our knowledge and leads an array for further immunization researches about immunological activities and molecular detection of spleen, which would be impossible without learning the basic anatomy.
\end{abstract}

Keywords: Anatomy, Post-natal development, Sonali chicken, Spleen

\section{Introduction}

A fundamental pattern of lymphoid tissues is their autonomous phylogenetic origin (Khalil, 2001). General knowledge of the composition of lymphoid tissue serves as a fundamental element in providing a detailed understanding of its physiology and immunology (Kaspers and Schat, 2008). It is well known that the pivotal components of the body defense mechanism are the innate and acquired arms. The innate immunity exhibits a non-specific immune response following the failure of the first line of body defense. On the contrary, an antigen-specific effector mechanism is used for adaptive immunity (Mishra, 2002).

As the largest secondary lymphoid organ, the spleen plays a range of beneficial roles in immune response, including clearing the bloodstream of the cells either infected or damaged and supplying the host with resistance to infection. In phylogeny, the chicken immune system has a vital role since it is without lymph nodes but has the Fabricius bursa (Lowenthal et al., 2013). Although, the red and white pulp with a distinct marginal zone consist the mammalian spleen paranchyma; there is lack of morphologically distinct marginal zone in chicken 
spleen (Jeurissen et al., 1992; Jeurissen, 1993; Igyártó et al., 2007; Biro et al., 2011). The white pulp is differentiated into three zones, those are-(A) PALS-at this region basically $\mathrm{T}$ lymphocytes adjoin the central arteries; (B) PELS-lymphoid tissue of B lymphocytes neighbours the branching penicillary capillaries; and (C) the lymph nodules-which is the primary site of B lymphocytes proliferations and differentiations. It is well known that the white pulp of chicken spleen have a vital role at the initial immune response (Gumati et al., 2003; Mebius and Kraal, 2005; Zhang et al., 2017).

The chicken spleen is a friable structure, soft, highly vascular, oval or rounded in shape and reddish-brown organ which lies dorsally to and near to the right side of the junction among the proventriculus and gizzard [Khalil, 2001; Akter et al., 2006; Ola 'h and Vervelde, 2008). Though detail works on immunohistology of spleen in broiler and deshi chicken have already done, no literatures were available regarding Sonali chicken, despite of playing a significant role in poultry industry as well as national economy in Bangladesh. In Sonali chicken, the morphohistology of bursa of Fabricius (Ayman et al., 2020a) and thymus (Ayman et al., 2020b) have already been investigated. So, the current research was designed to evaluate spleen of this bird at different postnatal stages using a histomorphometric approach.

\section{Materials and methods}

\subsection{Animal ethics}

The present study and all experimental procedures were approved and performed according to the regulations entrenched by Animal Welfare and Experimentation Ethics Committee, Bangladesh Agricultural University [AWEEC/BAU/2019(30)].

\subsection{Experimental design}

The experimental chickens (male) were reared at BAU poultry farm. During the whole experimental tenure biosecurity was regulated strictly. Much consideration was given to the feeding history, vaccination schedule as well at management practices. The collected chickens were free from any notable abnormalities. A total number of $25(\mathrm{~N}=25)$ chickens were used for the experiment and were divided into five age groups: $1^{\text {st }}$ day, $14^{\text {th }}$ day, $28^{\text {th }}$ day, $42^{\text {nd }}$ day, and $56^{\text {th }}$ day; $(\mathrm{n}=5)$.

\subsection{Tissue collection and preservation}

The experimental Sonali Chickens were slaughtered by cervical subluxation method at day 1, 14, 28, 42 and 56. The spleen samples were collected by dissection immediately after sacrificing of the birds and rinsed with physiological saline $(0.9 \%)$. Then the collected samples were immediately placed in Bouin's solution for further histological study. The investigation was conducted in the Department of Anatomy and Histology, Faculty of Veterinary Science, BAU, Mymensingh-2202, Bangladesh.

\subsection{Gross morphology}

Morphometric (i.e. color and weight, length, width and thickness) alterations of the spleen were examined in the Sonali chickens during the experiment. The color of the samples was recorded by visual inspection. The weight of spleen was recorded by electronic digital weighing balance while length, width, and thickness of the spleen were measured by slide calipers in scale of $\mathrm{mm}$. The gross anatomical images were taken straight from the organs by a digital camera.

\subsection{Histomorphology and biometric measurements}

For histological studies, the collected samples were dehydrated in the series of ascending graded alcohol followed by clearing in three changes of xylene. Then, the tissues were infiltrated with different grades of melted paraffin $\left(49^{\circ} \mathrm{C}, 55^{\circ} \mathrm{C}\right.$, and $\left.58^{\circ} \mathrm{C}\right)$ at 30 minutes interval. The tissues were then embedded in paraffin $\left(58^{\circ} \mathrm{C}\right)$ and finally the sections were cut at $6 \mu$ thickness using sliding microtome (MIC 509, Euromex, Japan). After cutting, the sections were floated in a floatation bath at $37^{\circ} \mathrm{C}$ for stretching. Then the sections were mounted on clean slides using an adhesive (egg albumins) and dried on a slide warmer at $37^{\circ} \mathrm{C}$. The sections were then stained using Mayer's Hematoxylin and Eosin (H \& E) stain. The histological characters of spleen were observed under light microscope at 10X and 40X magnifications. The length and breadth of white pulp and thickness of capsule were considered for biometric measurement which was performed using calibrated stage micrometer in $\mu \mathrm{m}$ (micrometer). Thirty sections (Six sections from each group) were biometrically evaluated from five different age groups of experiment. 


\subsection{Photomicrographs}

The sections were evaluated at 100 and 400 -fold magnification by Carl Zeiss Photomicroscope (Germany). For each section, six (06) randomly selected fields were captured.

\subsection{Statistical analysis}

The results were analyzed in the Statistical Package for the Social Sciences (SPSS; version 22.0) software. All data were expressed as mean \pm standard error mean and differences among the groups of birds were compared using one-way ANOVA with post-hoc Duncan's test. Values of $p<0.05$ were considered significant (Igbokwe and Ezenwaka, 2017).

\section{Results}

\subsection{Gross morphology of spleen}

The spleen of Sonali chicken was found lying dorsal and close to the right side of the junction between the proventriculus and gizzard (Figure $1 \mathrm{a}, \mathrm{b}$ ). The spleen of Sonali chicken appeared as a friable, soft, lymphoid organ with variable size and shape according to the age. The spleen was oval or rounded organ, reddish brown in color (Figure $1 \mathrm{a}, \mathrm{b}$ ).

In the course of experiment, the changes observed in the average weight, organ index, length, width and thickness of spleen of chicken presented in table 1. In all cases, highly significant numerical escalations were observed along with the increase of age.

\subsection{Histomorphology of spleen}

The histological architecture of spleen of Sonali chicken at day 1 of development was surrounded by a thin capsule (Figure 2a'). The capsule was composed of smooth muscle fibers and collagen fibers. No splenic trabeculae were present (Figure 2a). Microscopically, the spleenic parenchyma was made of red and white pulp with no identifiable marginal zone (Figure 2a). Histologically the spleen of Sonali chicken at day 14 of post natal growth was found similar to the day 1 with histological structural development (Figure 2b,b'). The central artery was found at this stage.

At day 28 of development, the thick splenic capsule was present without any trabeculae (Figure $2 \mathrm{c}^{\prime}$ ). The red pulp was distinct and these were scattered distributed within the white pulp. Central artery was found. At this stage of development, distinct lymphatic nodule was present within the parenchyma of spleen (Figure 2c). Histological feature of spleen of Sonali chicken at day 42 was similar to that of the day 28 with histological structures more developed than the previous groups (Figure $2 \mathrm{~d}, \mathrm{~d}^{\prime}$ ). Sheathed capillary was observed at white pulp (Figure 2d). The light microscopic study of spleen of the Sonali chicken at day 56 revealed that it was covered by a thick capsule with no trabeculae (Figure 2e, $\mathrm{e}^{\prime}$ ). The areas of red and white pulp were distinct throughout the spleen parenchyma. Sheathed capillaries were distinct in white pulp (Figure 2e).

\subsection{Biometric analysis of spleen}

\subsubsection{Thickness of capsule}

The biometry (thickness of capsule) of spleen had significant positive correlation with the age, i.e., the thickness of capsule was noticed gradually increasing throughout the experimental tenure $(12.54 \pm 1.617 \mu \mathrm{m}$ at day 1 to $32.34 \pm 5.754 \mu \mathrm{m}$ at day 56) (Figure 3).

\subsubsection{Length and breadth of white pulp}

During experimental period, the changes observed in the length and breadth of white pulp of spleen in different groups was showed in figure 4. Observation from the biometric study showed that the length of white pulp at $\mathrm{D}_{1}$ was $99.00 \pm 12.223 \mu \mathrm{m}$, at $\mathrm{D}_{14}$ was $153.02 \pm 29.722 \mu \mathrm{m}$, at $\mathrm{D}_{28}$ was $218.68 \pm 27.899 \mu \mathrm{m}, 323.14 \pm 35.654 \mu \mathrm{m}$ at $\mathrm{D}_{42}$ and at $\mathrm{D}_{56}$ the length of white pulp increased to $455.64 \pm 61.855 \mu \mathrm{m}$. Similarly, the breadth of white pulp was also measured. At $\mathrm{D}_{1}$ the breadth of the white pulp found $53.20 \pm 11.830 \mu \mathrm{m}, 93.40 \pm 21.915 \mu \mathrm{m}$ at $\mathrm{D}_{14}$, $116.54 \pm 23.061 \mu \mathrm{m}$ at $\mathrm{D}_{28}, 147.96 \pm 22.073 \mu \mathrm{m}$ at $\mathrm{D}_{42}$ and at $\mathrm{D}_{56}$ it was $296.22 \pm 15.819 \mu \mathrm{m}$. All changes were statistically significant. 
Table 1. Gross morphometric observations of spleen of Sonali chicken $(\mathrm{n}=5)$.

\begin{tabular}{|l|l|l|l|l|l|}
\hline Age group & Average weight $(\mathbf{g m})$ & Organ index $\mathbf{( \% )}$ & Length $(\mathbf{m m})$ & Width $^{(\mathbf{m m})}$ & Thickness $^{(\mathbf{m m})}$ \\
\hline Day 1 & $0.029 \pm 0.003^{\mathrm{a}}$ & $0.084 \pm 0.009^{\mathrm{a}}$ & $4.920 \pm 0.107^{\mathrm{a}}$ & $3.640 \pm 0.186^{\mathrm{a}}$ & $2.640 \pm 0.186^{\mathrm{a}}$ \\
\hline Day 14 & $0.169 \pm 0.009^{\mathrm{a}}$ & $0.182 \pm 0.007^{\mathrm{b}}$ & $8.580 \pm 0.271^{\mathrm{b}}$ & $5.780 \pm 0.337^{\mathrm{b}}$ & $5.300 \pm 0.295^{\mathrm{b}}$ \\
\hline Day 28 & $0.641 \pm 0.024^{\mathrm{b}}$ & $0.281 \pm 0.006^{\mathrm{c}}$ & $12.240 \pm 0.375^{\mathrm{c}}$ & $7.220 \pm 0.739^{\mathrm{b}}$ & $7.000 \pm 0.459^{\mathrm{bc}}$ \\
\hline Day 42 & $1.261 \pm 0.173^{\mathrm{c}}$ & $0.249 \pm 0.031^{\mathrm{c}}$ & $14.080 \pm 0.443^{\mathrm{d}}$ & $10.380 \pm 0.663^{\mathrm{c}}$ & $9.380 \pm 1.035^{\mathrm{c}}$ \\
\hline Day 56 & $2.795 \pm 0.110^{\mathrm{d}}$ & $0.389 \pm 0.011^{\mathrm{d}}$ & $19.840 \pm 0.571^{\mathrm{e}}$ & $13.4000 .431^{\mathrm{d}}$ & $12.480 \pm 1.380^{\mathrm{d}}$ \\
\hline p-value & $<0.001$ & $<0.001$ & $<0.001$ & $<0.001$ & $<0.001$ \\
\hline
\end{tabular}

Values with different letters $(\mathrm{a}, \mathrm{b}, \mathrm{c}, \mathrm{d}, \mathrm{e})$ within the same column differ significantly. Mean \pm standard error mean.

Day 1

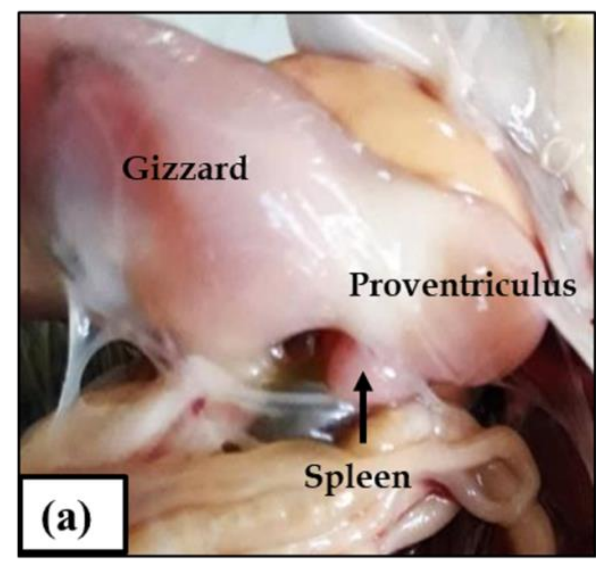

Day 56

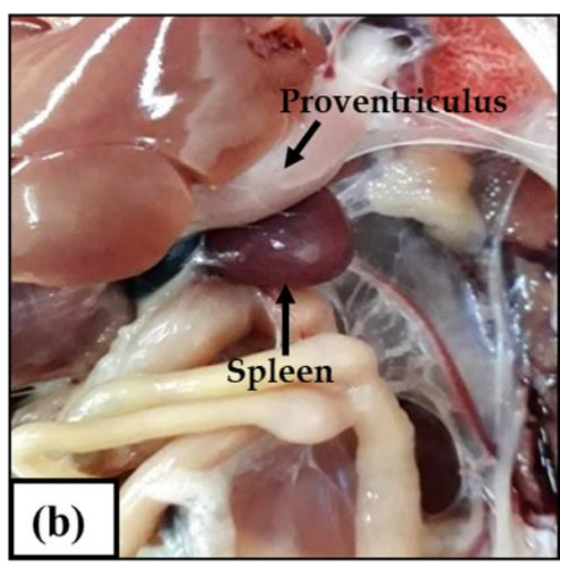

Figure 1. Representative photographs of the spleen of Sonali chicken, showing gross changes between day 1 and day 56.

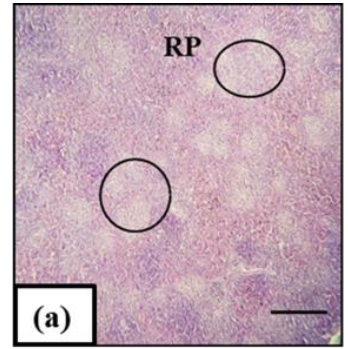

Day 1

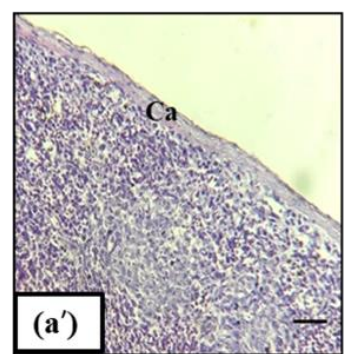

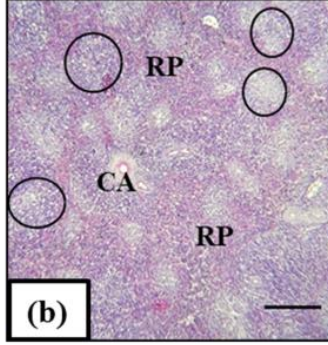

Day 14

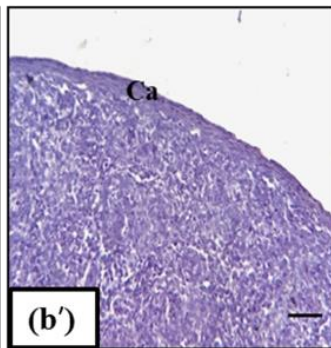

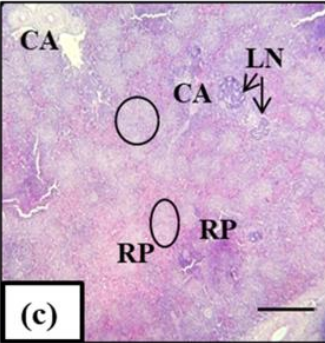

Day 28

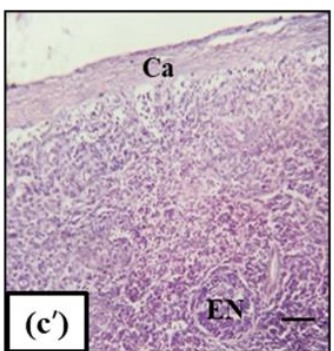

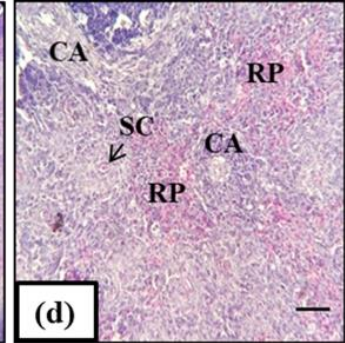

Day 42

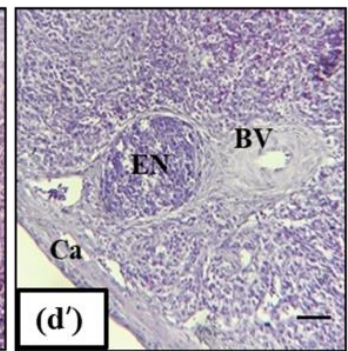

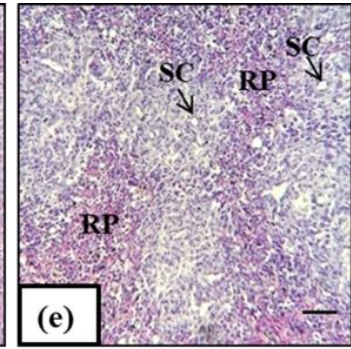

Day 56

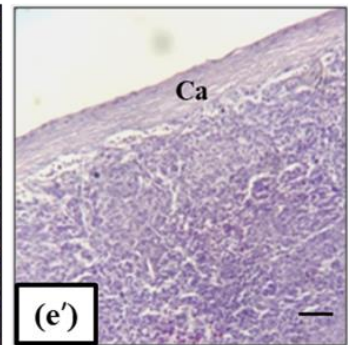

Figure 2. Histological representation of spleen of Sonali chicken at different post-hatching ages at $10 \mathrm{X}$ and 40X magnifications. RP- Red pulp; CA- Central artery; LN- Lymphatic nodule; SC-Scheathed capillary; BV- Blood vessel; EN- Encapsulated lymphatic nodule; Ca- Capsule; Circle- White pulp. Scale bar: $5 \mu \mathrm{m}$ and $1 \mu \mathrm{m}$. 


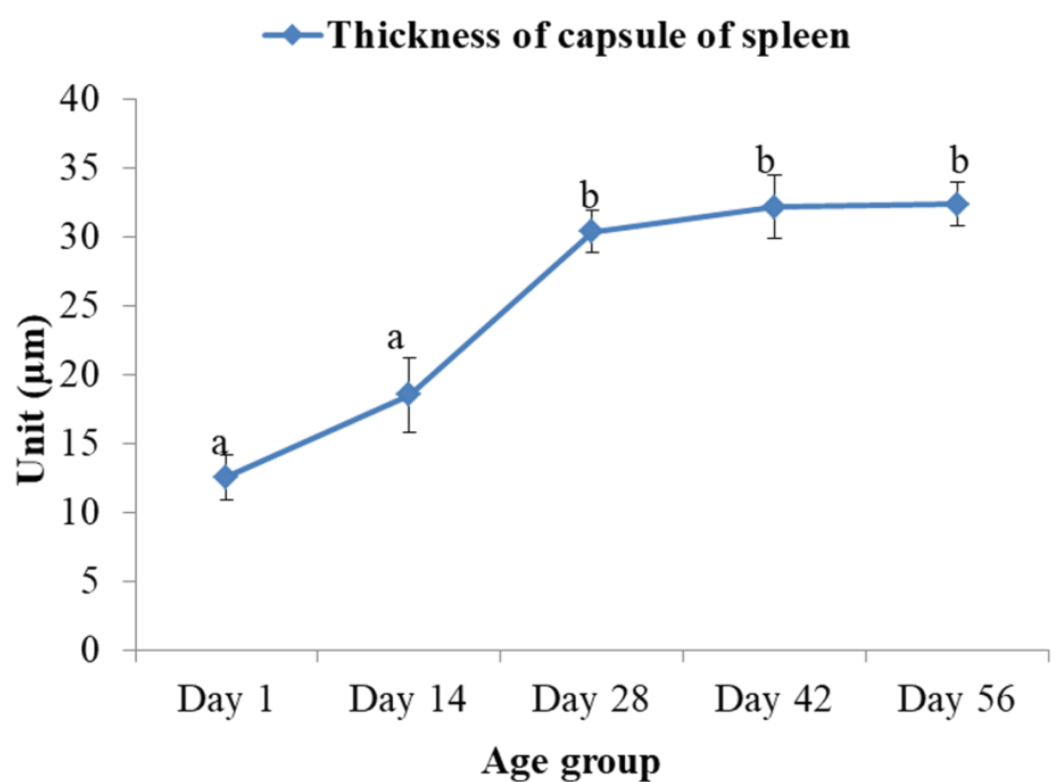

Figure 3. Effect of age on thickness of capsule of spleen during experimental tenure. Data were expressed as mean \pm standard error mean and differences among the groups were compared using one-way ANOVA with posthoc Duncan's test. *Line with differing superscripts $(a, b)$ significantly different from each other $(\mathbf{p}<0.05)$.

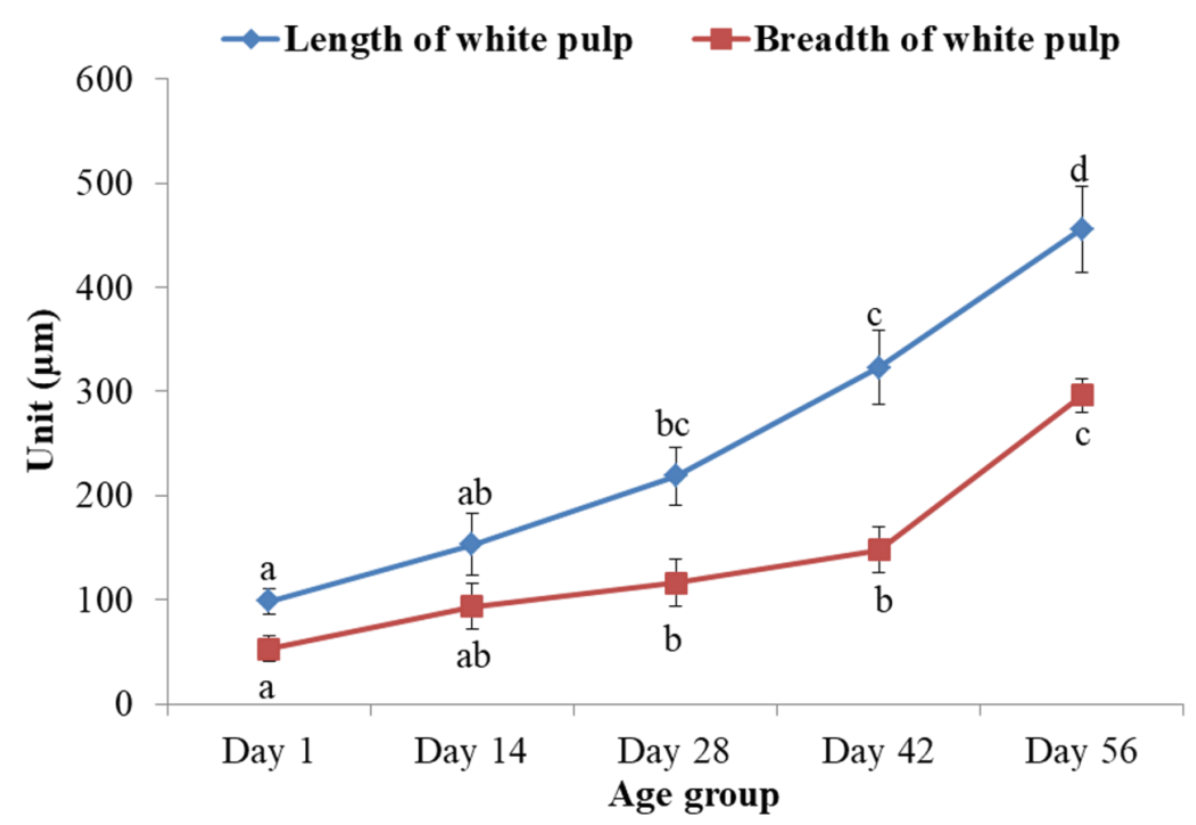

Figure 4. Effect of age on length and breadth of white pulp of spleen during experimental tenure. Data were expressed as mean \pm standard error mean and differences among the groups were compared using one-way ANOVA with posthoc Duncan's test. **Line with differing superscripts (a,b,c,d) significantly different from each other $(\mathbf{p}<0.01)$.

\section{Discussion}

In the present study the spleen of Sonali found lying dorsal to and close to the right side of the junction among the proventriculus and gizzard. The shape of the spleen in the present study revealed oval or rounded having reddish brown color during post natal stages of development. The gross findings found in present experiment were similar with the reports of (Khalil, 2001) in deshi chicken and (Akter et al., 2006) in broiler chicken. The average weight of spleen in the present study found to be gradually increasing throughout the whole study 
period during post natal stage $(0.029 \pm 0.003 \mathrm{gm}$ at day 1 and increased to $2.795 \pm 0.110 \mathrm{gm}$ at day 56). According to the previous report (Hodges, 1974), the size and weight of the spleen vary at different ages in different breed and in the same breed under different conditions. The average weight of spleen of broiler or deshi chicken found to be increasing throughout the whole study period which was reported by (Khalil, 2001; Khan et al., 2014). In Sonali chicken the length, width and thickness of spleen was significantly increasing up to day 56 indicating the developmental progress which agree with the findings of (Khalil, 2001; Khan et al., 2014). The spleen of Sonali chicken at postnatal stages of development was surrounded by a thin capsule. Smooth muscle fibers and collagen fibers were notified in the spleen. There were no Splenic Trabeculae. The splenic parenchyma was composed of red pulp and white pulp with blood vessels. The red pulp was distinct and these were scatteredly distributed among the white pulps. The general histological structure of spleen of Sonali chicken found similar to the other breeds of chicken reported before (Akter et al., 2006; Khan et al., 2014). But some distinct features were observed in Sonali chicken. Within the splenic parenchyma, there were no lymphatic nodules at hatching day. But as age increases, the lymphocytes begin to aggregate (at day 14) and finally distinct encapsulated lymphatic nodules were present (from day 28 onwards) which was gradually become more developed and increased in size according to age. At earlier findings, the appearance of lymphatic nodules in the parenchyma was mentioned but not the time of appearance (Khalil, 2001; Akter et al., 2006; Khan et al., 2014). So the time frame of appearing the lymphatic nodules may be different due to breed variation. In the present study it was found that the histological length and breadth of white pulp and thickness of capsule were significantly increased from day 1 to day 56. Previously similar result was reported (Khan et al., 2014).

\section{Conclusions}

From the present result it was notified that there is a strong correlation between the histological development and morphometric shift of spleen at post hatching ages. However, in experiment, no trabeculae as well as no identifying marginal zone was recorded in the splenic parenchyma of Sonali chicken. The results of this study gives an insight about the age correlated development of spleen of Sonali chicken at different age intervals which leads an array for further immunization researches to have in depth idea about immunological activities and molecular detection of spleen.

\section{Acknowledgements}

The authors appreciate the research assistance from the Department of Anatomy and Histology, Faculty of Veterinary Science, Bangladesh Agricultural University, Mymensingh, Bangladesh We acknowledge the technical support from the Department of Parasitology, Faculty of veterinary science, Bangladesh Agricultural University, Mymensingh, Bangladesh Ummay Ayman was awarded with the NST fellowship [Grant number: 1005/499] from the Ministry of Science and Technology, Bangladesh to conduct the research.

\section{Conflict of interest}

None to declare.

\section{References}

Akter SH, MZI Khan, MR Jahan, MR Karim and MR Islam, 2006. Histomorphological study of the lymphoid tissues of broiler chickens. Bangl. J. Vet. Med., 4: 87-92.

Ayman U, MR Alam and SK Das, 2020a. Age-related development and histomorphological observations of bursa of Fabricius in sonali chicken. J. Adv. Biotechnol. Exp. Ther., 3: 20-28.

Ayman U, MR Alam and SK Das, 2020b. Post-natal macro- and microscopic changes of the thymus of Sonali chicken in Bangladesh. J. Adv. Vet. Anim. Res., 7: 324-330.

Biro E, K Kocsis, N Nagy, D Molnar, S Kabell, V Palya and I Olah, 2011. Origin of the chicken splenic reticular cells influences the effect of the infectious bursal disease virus on the extracellular matrix. Avian Pathology, 40: 199-206.

Gumati MK, A Magyar, N Nagy, E Kurucz, B Felfoldi and I Olah, 2003. Extracellular matrix of different composition supports the various splenic compartments of guinea fowl (Numida meleagris). Cell Tissue Res., 312:333-343.

Hodges RD, 1974. The Histology of the Fowl. London: Academic Press, 84:180-187.

Igbokwe CO and K Ezenwaka, 2017. Age related morphological changes in the thymus of indigenous Large White pig cross during fetal and postnatal development. Anatomy, 11: 12-20. 
Igyártó BZ, A Magyar and I Oláh, 2007. Origin of follicular dendritic cell in the chicken spleen. Cell Tissue Res, 327: 83-92.

Jeurissen SH, E Claassen and EM Janse, 1992. Histological and functional differentiation of nonlymphoid cells in the chicken spleen. Immunology, 77: 75-80.

Jeurissen SH, 1993. The role of various compartments in the chicken spleen during an antigen specific humoral response. Immunology, 80: 29-33.

Kaspers B and K Schat, 2008. Avian immunology. Academic Press is an imprint of Elsevier, $1^{\text {st }}$ edition. https://www.elsevier.com/books/avian-immunology/kaspers/978-0-12-370634-8.

Khan MZI, Md Masum, ZI Khan, ARB Aziz, M Nasrin, NH Siddique, et al, 2014. Histopmorphology of the lymphoid tissues of broiler chickens in Kelantan, Malaysia. Sains Malays, 43: 1175-1179.

Lowenthal JW, AGD Bean and MH Kogut, 2013. What's so special about chicken immunology? Dev. Comp. Immunol., 41: 307-309.

Mebius RE and G Kraal, 2005. Structure and function of the spleen. Nat. Rev. Immunol., 5: 606-616.

Mishra UK, 2002. Structural and functional development of immunity in chicks. MS Thesis. G.B. Pant University of Agriculture \& Technology PANTNAGAR-263 145, (U.S. NAGAR), Uttaranchal, INDIA.

Khalil M, 2001. Age related histomorphological changes of lymphoid organs of deshi chicken of Bangladesh. MS thesis. Department of Anatomy and Histology. Bangladesh Agricultural University, Mymensingh-2202.

Ola ' $h$ I and L Vervelde, 2008. Structure of the Avian Lymphoid System. Avian immunology. Fred Davison, Bernd Kaspers, Karel A. Schat (editors). Elsevier Academic Press INC., 13-50.

Zhang Q, Y Waqas, P Yang, X Sun, Y Liu, N Ahmed, B Chen, Q Li, L Hu, Y Huang, H Chen, B Hu and Q Chen, 2017. Cytological study on the regulation of lymphocyte homing in the chicken spleen during LPS stimulation. Oncotarget, 8: 7405-7419. 